\title{
Conceptual Change in Language Teaching and Learning: Why and How Lexical Concepts Drive Meaning Construction Differently across Languages
}

\author{
Sebastian Feller \\ A*STAR - Institute of High Performance Computing, Social Situation Awareness Group, 1 Fusionopolis Way, \#16-16 \\ Connexis, Singapore
}

\begin{abstract}
Teaching and learning based on conceptual change, henceforth TaLCC, have increasingly gained momentum in education. This development stems from recent findings that TaLCC facilitate learner's deep reasoning and profound understanding of complex problems. One explanation for this is TaLCC's scaffolding of self-regulated learning, which, as argued by Self-Determination Theory (e.g. Deci and Ryan 1985), facilitates learner motivation and learning performance. In this paper I adapt the basic assumptions of TaLCC to language teaching and learning. The focus of this paper is on word meaning and vocabulary learning. On the basis of Evans' (e.g. 2006) Lexical Concepts and Cognitive Models Theory I explicate word meaning via socalled cognitive model profiles. I outline a method for language learners to construct cognitive model profiles from a word's co-textual environment explicating and contrasting lexico-semantic regularities and idiosyncrasies of translation equivalents in the learner's L1 and the target language.
\end{abstract}

Index Terms - conceptual change, vocabulary learning, cognitive models, meaning construction, meaning-inuse, dialog, language teaching and learning

\section{INTRODUCTION}

Theories of conceptual change learning have drawn much attention in education in general and language learning in particular (e.g., Brophy 2010; Torres and de Cássia Veiga Marriott 2010; Fraser et al. 2011; Zimmerman and Schunk 2011). One of the basic assumptions of teaching and learning based on conceptual change, henceforth TaLCC, is that learners have their own views and ideas of things from the very beginning. In order to cope with the world learners naturally construct their own "theories" about how things are, long before teachers introduce them to scientific explanations.

This insight is not trivial. It presumes that teaching and learning take place on top of existing knowledge and not in an information vacuum. Learners are not blank slates where information is merely written on. In contrast, new knowledge builds up on what the learner already knows. This knowledge also includes everything the learner knows from and about the "real world" outside of the classroom. Within this context, learning is rather about replacing, revising, and extending existing knowledge than about filling a tabula rasa (cf., e.g., Haenen et al. 2003, p. 247; Meadows 2008, p. 181; Sinatra 2011).

Within this context, other findings in educational science gain plausibility. For example, studies have found positive effects of dialog and collaboration on learning (cf. Alexander 2004; Craig et al. 2000; Fisher 2007). Proof has accumulated over the past years that dialogic teaching and learning facilitate deep conceptual understanding, knowledge retention, the overcoming of misconceptions, and increase creativity in the learner. Classroom discussions or questioning and answer conversations help learners process information on a higher level of thinking and tackle problems in a much more comprehensive and inventive manner. The success of these teaching and learning strategies can be explained by conceptual change learning. Dialog gives teachers an opportunity to probe into the learner's existing knowledge. In this way, teachers can take existing learner knowledge into account when introducing a new topic, helping learners to build new knowledge on top of knowledge they already possess. Teachers get an opportunity to customize their teaching to the learner's needs by finding out about their knowledge states and conceptualizations of a problem including knowledge gaps, relevant conceptions as well as misconceptions.

The aim of this paper is to expand TaLCC to language teaching and learning. I will argue that TaLCC can and should be used in the language classroom. The focus of this paper is thereby on vocabulary learning. I argue that TaLCC faciliate vocabulary learning, proposing a view of vocabulary learning as conceptual change based on the translation equivalents in the $\mathrm{L} 1$ and the $\mathrm{L} 2$.

In section 2 I give an overview of the general idea behind conceptual change learning within the context of an example from science education. In section 3 I first introduce Evans' (2006; 2009) Lexical Concepts and Cognitive 
Models Theory (LCCM), which I use to explicate word meaning via so-called cognitive model profiles. This lays the foundation for the conceptual change view of vocabulary learning that I propose here. I furthermore argue that words are meaningful only as words-in-context and that different ways-of-use of a word correlate to distinct meanings. These differences in meaning can be explained on the basis of what I call soft conceptual change. As I will illustrate, soft conceptual change results from variations of semantic affordances, i.e. associative meanings of an expression that are determined by the semantics of the co-text it appears in. I will argue that translation equivalents always appear in different co-texts with different semantics. Conceptual change is thus a strategy to translate form L1 to L2. Section 4 applies this framework to the learning of words of a second or foreign language. Based on the view of meaning-in-use, which I briefly discuss in section 4.1. and which I laid down in more detail elsewhere (Feller 2010), I show in section 4.2. that TaLCC scaffold the "correct" processing of translation equivalents. I furthermore argue that reflecting on the differences in how languages conceptualize the world in the translation process strengthens both the learner's understanding of lexico-semantic characteristics in his L1 as well as in the target language. This helps the learner to avoid misinterpretations in the L2 caused by, for example, L1 transfer. In section 5 I discuss some of the practical implications for the language classroom, followed by my concluding remarks in Section 6.

\section{WhAt Is CONCEPTUAL CHANGE}

Conceptual change is based on the idea that new knowledge is built on top of existing knowledge. In other words, an individual who learns something new is not a blank slate. New knowledge is always created through changing existing knowledge in one way or another (cf., e.g., Hewson 1992; Thagard 1992). Knowledge is thereby defined as an individual's existing conceptualizations about the world and the things therein.

Let me illustrate this point by the following example which is taken from a tutoring session about electricity (transcript online at http:// talkbank.org/browser/index.php?url= Tutoring/Circle/Electricity/25.cha; last accessed on 10 Oct., 2012; line numbers and spelling mistakes from original):

8 *TUT: $\quad$ what is it that the lighbulb needs [= the one most important thing]

$9 \quad$ in order to light up?

$10 *$ STU: $\quad$ heat.

11 *TUT: $\quad$ hmm.

12 *TUT: $\quad$ well, think about it this way, if you put a lightbulb in the oven,

13 it would certainly be getting lots of heat, but would it be likely

14 to light up?

In this part of the interaction the teacher wants to get to know the learner's existing conceptualization of a simple electrical circuit around a light bulb. His initial question what the light bulb needs to light up (lines 8-9) makes the learner communicate his view of how things work out in the circuit. From the answer in line 10 we can assume that the learner entertains the following conceptualization: [heat] $\rightarrow$ [light bulb lights up]. The words in square brackets stand here for concepts, i.e. mental representations of things in the world. The arrow represents a causal relation between the concepts: $x$ causes $y$. As for the given case, this means that the learner believes that heat causes the light bulb to light up

This conceptualization does obviously not match the current standard scientific explanation. With a view to tackling the learner's misconception, the teacher applies a hidden negative in question form in lines 12-14. The use of 'but' in line 13 thereby hints at the absurdity of the learner's explanation. Within this context, the learner feels the need to revise his initial conceptualization. More precisely, the teacher creates a need for the learner to replace [heat] with a different concept as a cause. This need is thereby based on dissatisfaction (cf. also Hewson 1992, p. 9), i.e., the learner now sees that his initial conceptualization does not work and must be changed ultimately.

And indeed, in his next move the learner offers an alternative. He replaces [heat] with the new concept [wires] (see line 15). As this conceptualization is again off the mark, the teacher applies the same strategy as before, using a hidden negative in question form (lines 16-17).

15 *STU: $\quad$ wires.

16 *TUT: $\quad$ wires help, but if you hook a wire to a light bulb and nothing else,

17 will it light up?

18 *STU: no, I guess it must be the voltage source.

19 *TUT: $\quad$ right, there needs to be electricity.

The learner goes along, again changing his conceptualization. He replaces [wires] with [voltage source] (line 18), finally meeting the teacher's approval (line 19).

To sum up: in the given example learning takes place via conceptual change. The teacher inquires about the learner's existing conceptualization of the problem. Having detected existing misconceptions, he instigates a need in the learner to change these misconceptions.

It is important to note that conceptual change comes in different degrees. Generally speaking, conceptualizations might either be revised in the sense that they get either extended or truncated, get completely replaced or discarded altogether (cf. Hewson 1992, pp. 3ff.). While in the first two cases the existing conceptualization is modified while still remaining intact, in the latter two cases the existing conceptualization is tossed out from the learner's knowledge base. 
We will see that for vocabulary learning, it is mostly the first two types of conceptual change which play a prominent role.

\section{CONCEPTS AND MEANING CONSTRUCTION: LCCM THEORY}

In this chapter I will give a brief outline of Evans' (2006) Lexical Concepts and Cognitive Models Theory (LCCM) followed by a definition of meaning construction. This lays the basis for the discussion of what I call semantic affordances and soft conceptual change in section 4, which both lie at the heart of TaLCC as proposed in this paper.

\section{A. Cognitive Representations of Word Meaning}

LCCM Theory is based on the assumption that words give access to what Evans calls cognitive model profiles (2006, pp. 519ff.). Cognitive model profiles are conceptual maps which consist of so-called cognitive models. As an example, I have constructed the cognitive model profile for 'Obama' below:

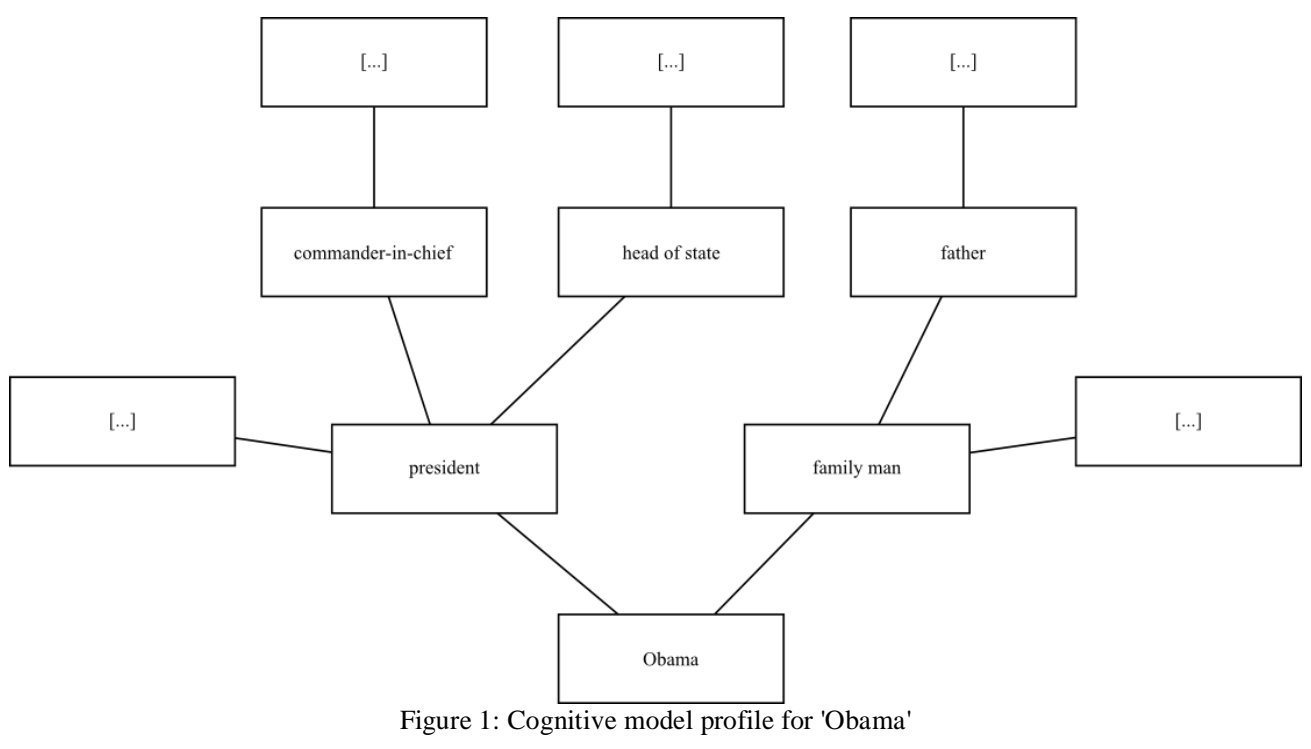

The boxes stand for cognitive models, i.e. chunks of encyclopedic information in an individual's knowledge base that relate to particular aspects of the world associated with the base cognitive model, which, in the present case, is [Obama]. The base model is connected to a further layer of cognitive models: so-called primary cognitive models. Primary cognitive models represent knowledge immediately associated with the base cognitive model. The primary models are connected to the secondary cognitive models located on the next layer, representing knowledge which is only indirectly connected to the base model. For example, as illustrated by Figure 1, [Obama] is connected to the primary cognitive models [president] and [family man], which are divided further into secondary cognitive models. [president], for instance, is connected to the secondary models [commander-in-chief] and [head of state].

As indicated by "[...]", this cognitive model profile is only a partial representation of the full potential knowledge associated with [Obama]. Other cognitive models can be added to the profile. The depth of detail of a profile thereby depends on the purpose of the representation. For example, a language learner might require a high level of detail in order to get acquainted with the subtleties of meaning of an expression. In the same vein, more technical purposes demand a close eye for detail which might not be required in everyday speech. Consequently, the depth of a profile is to be adjusted accordingly.

\section{B. Meaning Construction}

It is cognitive models in cognitive model profiles that are at the core of meaning construction. In language use cognitive models within given cognitive model profiles are selected through matching processes at the level of the utterance (cf., e.g., Evans 2010b, pp. 19ff.). In other words, meaning is constructed by matching specific cognitive models across profiles of different words within a relevant co-textual span. Consider the following examples from the Corpus of Contemporary American English, henceforth COCA (online at http://corpus.byu.edu/coca; last accessed on 13 Aug., 2012):

(1) Obama always intended to continue combating terrorism, but he did not embrace Bush's concept of a "global war on terror." (COCA)

(2) Against the backdrop of Disney's Cinderella castle, Obama announced initiatives aimed at making it easier for citizens of China and Brazil to visit the United States. (COCA)

The difference in meaning of 'Obama' in (1) and (2) becomes obvious against the backdrop of the selected cognitive models in the profile of [Obama]. In (1) 'Obama' is interpreted against the secondary cognitive model [commander-in- 
chief], while (2) points to the secondary cognitive model [head of state]. But how does meaning construction in such cases work exactly? The following section provides a first answer.

\section{Semantic Affordance and Soft Conceptual Change}

There can be little doubt that (1) and (2) yield different interpretations of 'Obama'. The question is why. The answer lies in the words that are in the co-text. Hereto consider the following:

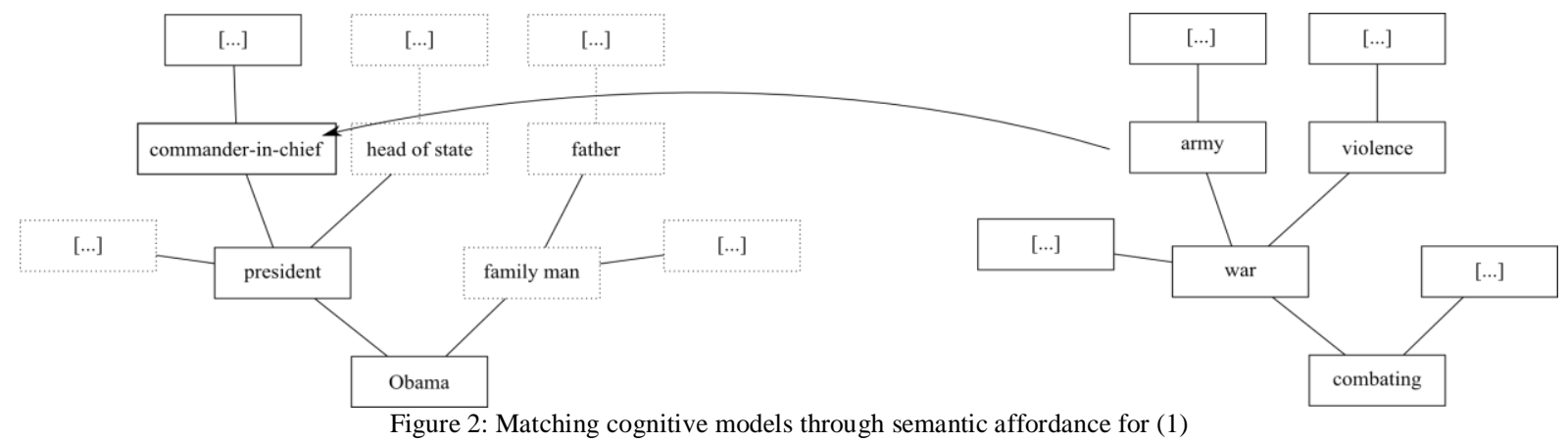

Figure 2 illustrates how meaning construction works in the given case. Semantic affordances associated with the relevant cognitive models from the cognitive model profiles of the words in the co-text of 'Obama' (i.e. the predicate here) select relevant cognitive models from the profile of 'Obama' (Evans 2010a, pp. 642ff.). By semantic affordances I mean inferences based on associative information connected to a particular cognitive model. As for (1), it is the gerund 'combating' which is important for the meaning construction. The secondary cognitive model [army] of [combating] connects with the secondary cognitive model [commander-in-chief] of [Obama] via inferences based on associative information around both models. For example, [army] is associated with "obeying orders", "defending one's country", and "going to war", amongst others. [commander-in-chief], on the other hand, incorporates associations like "giving orders", "operational planning", and "leadership". Comparing these two sets of associations, a coherent conceptualization emerges. "obeying orders" is a reaction to the initial action "giving orders" just like "defending one's country" as goal connects with "operational planning" as a means to reach this goal, and so forth.

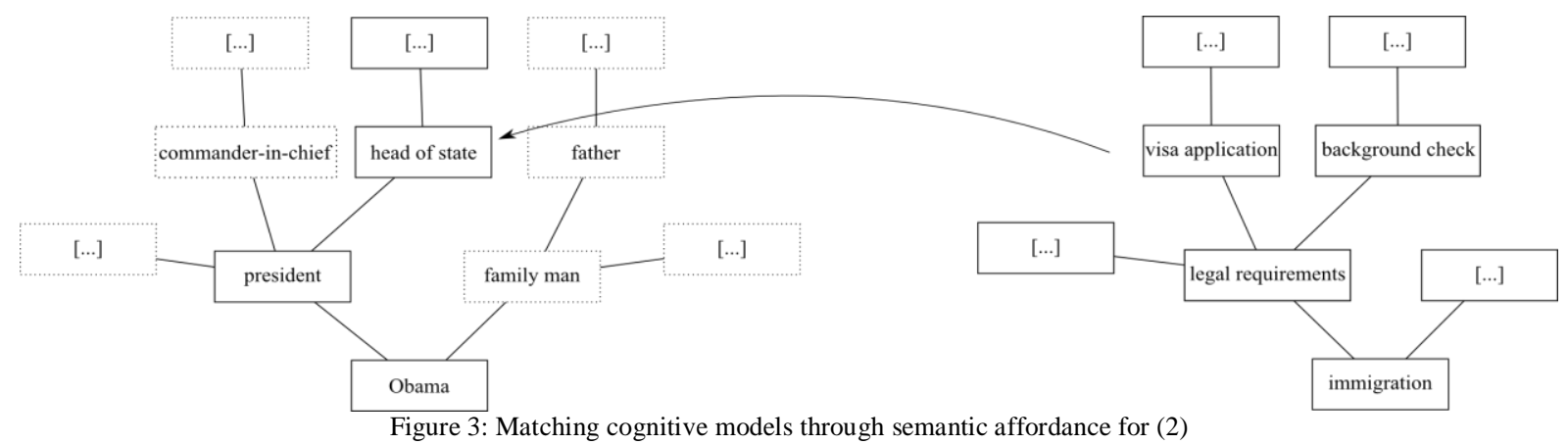

As we can see in Figure 3, the matching process works similarly for (2). Here a coherent construction emerges from [visa application] of [legal requirement], which combines with [head of state] of [Obama] (Note that to simplify the figure I represent 'citizens of China and Brazil to visit the United States' by [immigration]. A more detailed representation would need to take into account further specifications connected to 'citizens of China' and 'citizens of Brazil' and the specific visa regulations by US immigration for these particular national groups. This however lies beyond the purpose of this illustration.). Semantic affordances including associations like "signing immigration laws", "protecting the nation", "granting immigration and naturalization" and "directing the nation's course of foreign affairs" of [head of state] as well as "entering the US on a temporary basis", and "seeking permission to visit the US for business" or "seeking permission to visit the US for pleasure" of [visa application] all connect to a coherent picture of mutually related actions and reactions including people's related interests and intentions in the construed conceptualization.

To sum up, the different interpretations of 'Obama' in (1) and (2) are selected by means of inferences evoked by the word's co-textual environment. The interpretations result from the matching of cognitive models of the keyword (i.e., in the given case, 'Obama') and relevant words in the near co-text via semantic affordances.

The different meanings in (1) vs (2) are thereby instances of what I call soft conceptual change. Getting from the interpretation of 'Obama' in (1) to the one in (2) is not based on conceptual change in the radical sense by which a concept gets replaced with a new concept or discarded entirely. In the given example, the concept is not even extended or truncated. The change is rather a question of activating or accentuating different parts of the same cognitive model profile. That means that while for (1) the interpretation of 'Obama' focuses on [commander-in-chief] the other cognitive 
models like [head of state] or [family man] are still intact but remain solely in the background of the conceptualization. This selection of models occurs for (2) accordingly.

This does not exclude more radical forms of conceptual change per se. For example, somebody who is not aware of the fact that the President of the United States is also commander-in-chief might extend his cognitive model profile of 'Obama' by [commander-in-chief] after encountering (1). A concept might also be fully replaced with a new concept. Imagine somebody thought that Obama was a famous physicist. On encountering (1) or (2), he would need to replace this conceptual model profile almost entirely. I am not looking into these more radical forms of conceptual change in this paper and leave this to future research. We should note, though, that this is needed for a more complete understanding of what is going on in the meaning constructing process.

The important point here is that single words are literally meaningless for meaning construction. It is first of all the larger co-textual environment of a word in use which selects relevant cognitive models within a given profile. This word-in-context view goes hand in hand with other theories of meaning, especially those that stand in the tradition of corpus linguistics like Sinclair (1991), and Stubbs (2001), as well as pragmatic theories of meaning like Weigand (2005), and Vanderveken (2009).

So far I have somewhat begged the question of which and how many words exactly in the co-text of a keyword are to be considered for meaning construction. The answer here is simple: those words and only those that make sense, i.e. that are useful and relevant for constructing a coherent picture of the state of affairs or part of the world being expressed.

Corpus linguists like Sinclair $(1991 ; 1998)$ or Mason (2007) have given a systematic answer based on word statistics. They argue that a word span of about three to four words to the left and right might mostly be significant for a speaker's constructing meaning of a given keyword. The neighboring words within this span are largely stable and therefore seem to form larger units of meaning. However, this quantitative approach cannot really describe let alone explain how meaning construction actually works. For this one has to leave the level of the text and move on to the level of cognition. Frequent co-occurrence of words might signal some sort of semantic relations but it does not settle the issue per se.

My answer is that the solution lies in the conceptualization expressed by a speaker. Unless we arrive at a more detailed understanding of how the speaker conceptualizes the world and maps his conceptualizations to language we are confronted with a paradoxical situation: on the one hand, it is first of all the words that give rise to a conceptualization. At the same time, however, we are in need of a conceptualization to determine what words to include in meaning construction. The key to overcome this contradiction is thereby to understand the exact nature of the relationship between conceptualizations and meaning construction. Assuming, for example, that language maps to conceptualizations by convention and that these mappings are part of a speaker's linguistic competence, speakers would not have any trouble to identify relevant words in the co-text of a keyword for meaning construction. How this mapping might work exactly is however beyond the scope of this paper and must be dealt with elsewhere.

\section{Soft Conceptual Change And LANGuage LeARning}

In this section, meaning construction based on soft conceptual change will be applied to translating between languages. The main question is how speakers interpret translation equivalents and what kind of differences in meaning occur, if any. For this purpose I will first of all introduce the concept of meaning-in-use which is based on the idea that speakers of different languages conceptualize the world differently. In the next step, I will discuss selected examples of translation equivalents illustrating this kind of meaning relativity and discuss the consequences that result from there for meaning construction across different languages.

\section{A. Meaning-in-use}

Over the last decade more evidence has accumulated showing that how people perceive and conceptualize the world is relative. And this relativity also shows in the language people use. Leaving aside the intricacies of this line of research, I will only give a brief overview of some selected findings in the reminder of this section.

Levinson (2009), amongst others, provides a number of examples including conceptualizations of location and time. While some speaker groups conceptualize location based on egocentric coordinates, other groups use geocentric information. And this difference in conceptualization shows in the respective languages. For example, while an egocentric speaker would say The ball is on the left side of the tree, a geocentric speaker, on the other hand, would express the same situation as The ball is on the west side of the tree.

Everett's (e.g., 2005) research on native tribes in Brazil supports this relativity claim. For example, the Pirahã language does not have a perfect tense. On the other hand, present and past tense are encoded in the language. For Pirahã speakers something either happened in the past or is happening right now. But they never think of an activity as beginning in the past and continuing up to the present.

It is this relativity of interpreting and conceptualizing the world which lies at the heart of what I (e.g., Feller 2010, p. 34) called elsewhere meaning-in-use. Speakers interpret linguistic expressions by integrating encyclopedic and linguistic knowledge at once. Encyclopedic knowledge is pooled in how speakers cognize about the world as illustrated by the previous examples of location and time. Linguistic knowledge, on the other hand, refers to the form of a language including syntactical and lexical structures, amongst other. For example, what word class or what part of speech a word belongs to, or how to inflect verbs for tense, aspect, and mood are questions that fall in this category. 
This view of language has consequences for our understanding of meaning construction. As we have already discussed earlier and will see in more detail below, the traditional single-word perspective does not suffice to account for what is going on in meaning-in-use. It is not single words that map to speaker's conceptualizations but words-incontext. In addition, as we discussed earlier, meaning construction of different ways-of-use of a word is based on conceptual change. Taking cognitive relativity across speakers from different languages seriously, I hold that interpreting translation equivalents in an L1 and an L2 runs similarly along soft conceptual change. The next section looks into this in more detail.

\section{B. Selected Examples of Soft Conceptual Change for Interpreting Translation Equivalents}

As a first example, let us consider the following translation equivalents from English and Spanish.

(1) The thief ran out.

(2) El ladrón salió corriendo.

In (3), a satellite-framing construction, manner of the movement is encoded by the verb to run and [path] by the particle out. On the other hand, in (4), the Spanish equivalent, the verb salir encodes path, while manner is expressed through the participle corriendo, which is clearly a verb-framing representation of the action.

The important question here is whether this difference in how meaning is encoded across the predicate has actually consequences for how the sentences are interpreted as a whole. Representing the relevant cognitive model profiles will help shed some light on this question.

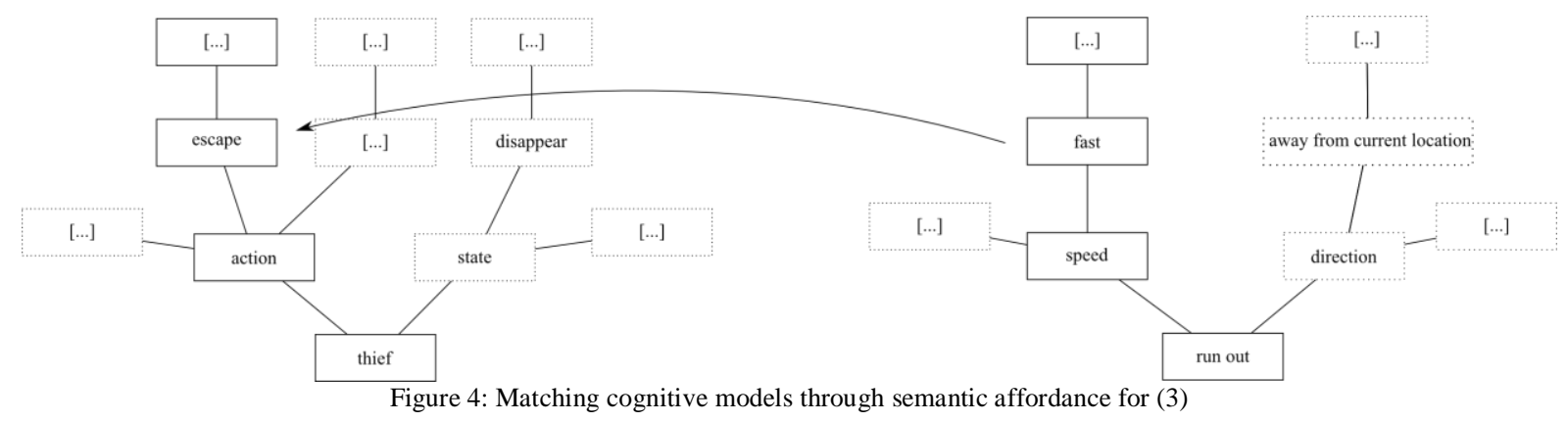

Figure 5 shows the matching of cognitive models for the Spanish translation equivalent.

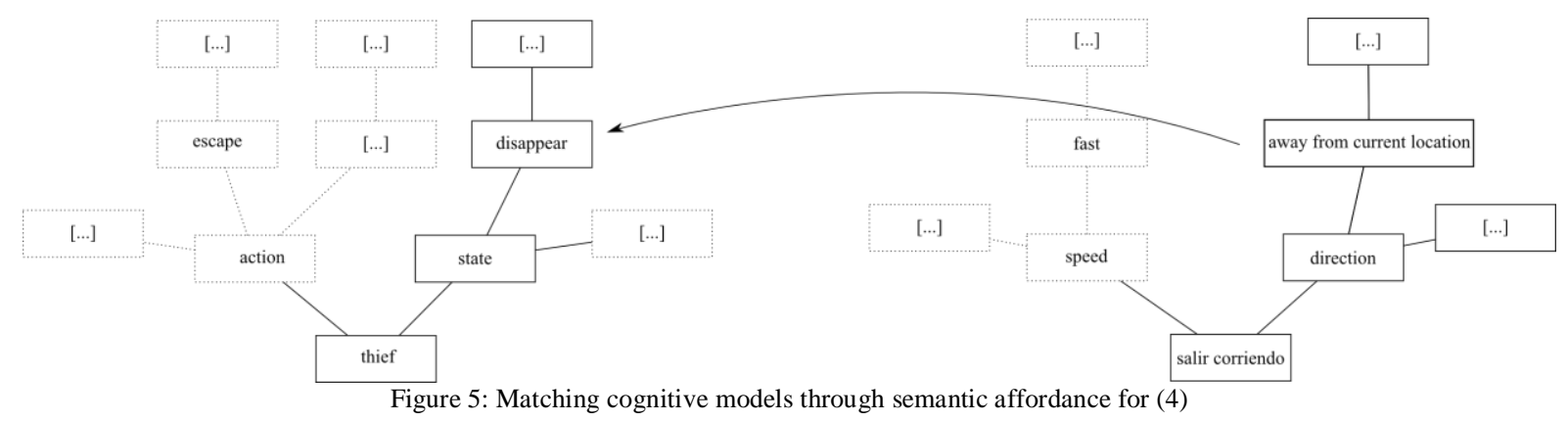

Comparing Figures 4 and 5 shows that the conceptualizations of the state of affair as expressed in English and Spanish differ. The cognitive models of [run out] and [salir corriendo] select different cognitive models in the cognitive model profile of [thief] (Note that in the figures both 'thief' and 'ladrón' are represented by [thief].)

In (3) the secondary cognitive model [fast] of [run out] connects to the secondary model [escape] of [thief]. [fast] selects [escape] via semantic affordances. A thief escapes by "moving faster" than his pursuer. What we are dealing with here is a sort of action reading of 'thief' which focuses on the referent's physical activation. The thief is running, i.e. he is physically in action. On the other hand, in (4), [direction] of [salir corriendo], which is connected to the secondary model [away from location], alludes to the referent's geographic state. The semantic affordances of [away from current location] like "getting out of sight" and "getting to a different place" point to the thief"s disappearing from the crime scene. The physical action itself is here only of secondary concern. The central idea is that the thief will be gone. We are dealing here with a state reading rather than an action reading of 'thief'.

The broken stroke again marks off those cognitive models that are activated only in the background of the conceptualization. This means that in (3) there is still a vague association with [state] of [thief] instantiated through the particle 'out'. Similarly, 'corriendo' in (4) distantly alludes to [action], while the state reading is at the center of the conceptualization.

Summing up, it is obvious that the English translation equivalent promotes a stronger motion imagery than the Spanish translation (cf. also Pavlenko 2002, p. 77). While in the former the focus is clearly on speed and movement, the latter emphasizes the end state of being gone or out of sight. Translating from (3) to (4) thus requires the speaker to 
engage in soft conceptual change. Only if he understands the semantic affordances of the respective cognitive models of 'to run out' and 'salir corriendo' will he be able to arrive at an adequate interpretation of 'thief' and 'ladrón' respectively. An English learner of Spanish, for example, would thus need to actively reflect on these conceptual differences in order to escape false interpretations such as transferring the action reading in English to the Spanish translation.

Let us take a look at a different example for German and English translation equivalents:

(1) Der Praesident trat sein Amt an.

(2) The president took office.

Again it is the distinct semantic affordances of the predicates that select specific cognitive models in the cognitive model profiles of the subjects, i.e. in the given cases, 'der Praesident' and 'the president' respectively. (Note that both 'der Praesident' and 'the president' are represented by the same cognitive model [the president]. Broken stroke is used once more for conceptual models that are activated as background knowledge.)

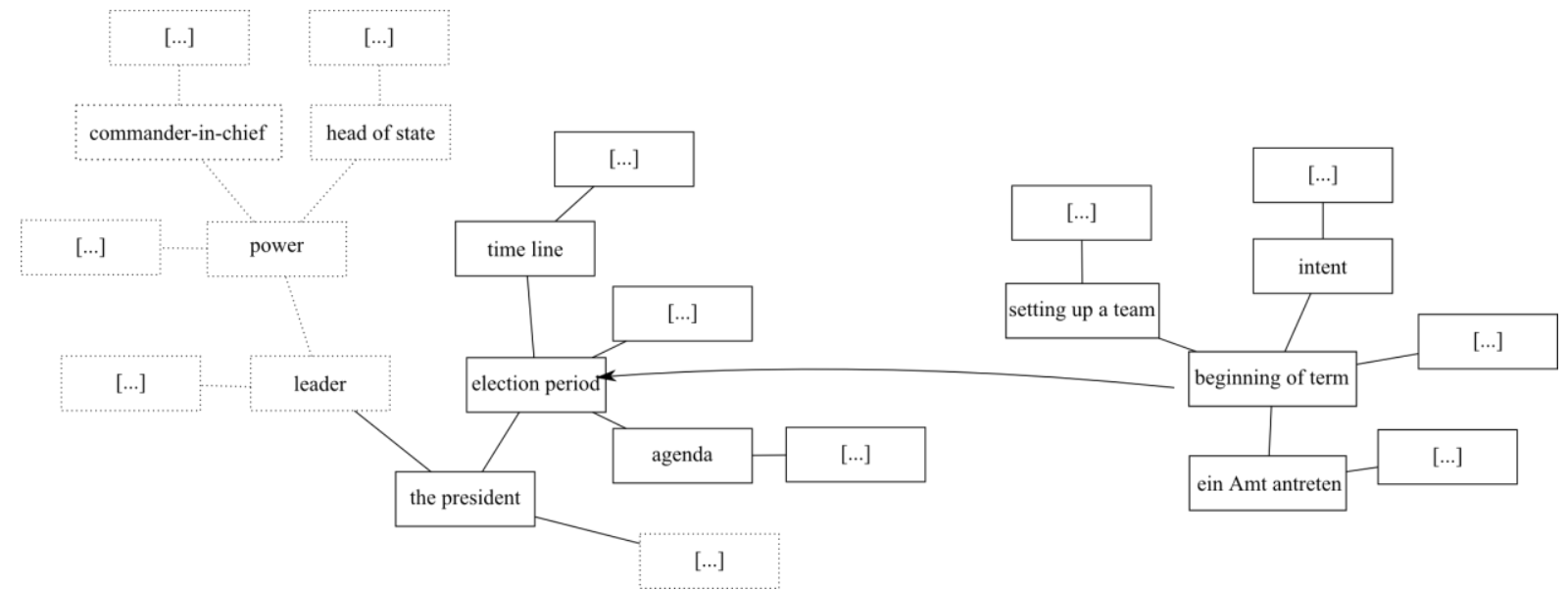

Figure 6: Matching cognitive models through semantic affordance for (5)

Figure 7 illustrates how the cognitive models are matched for (6).

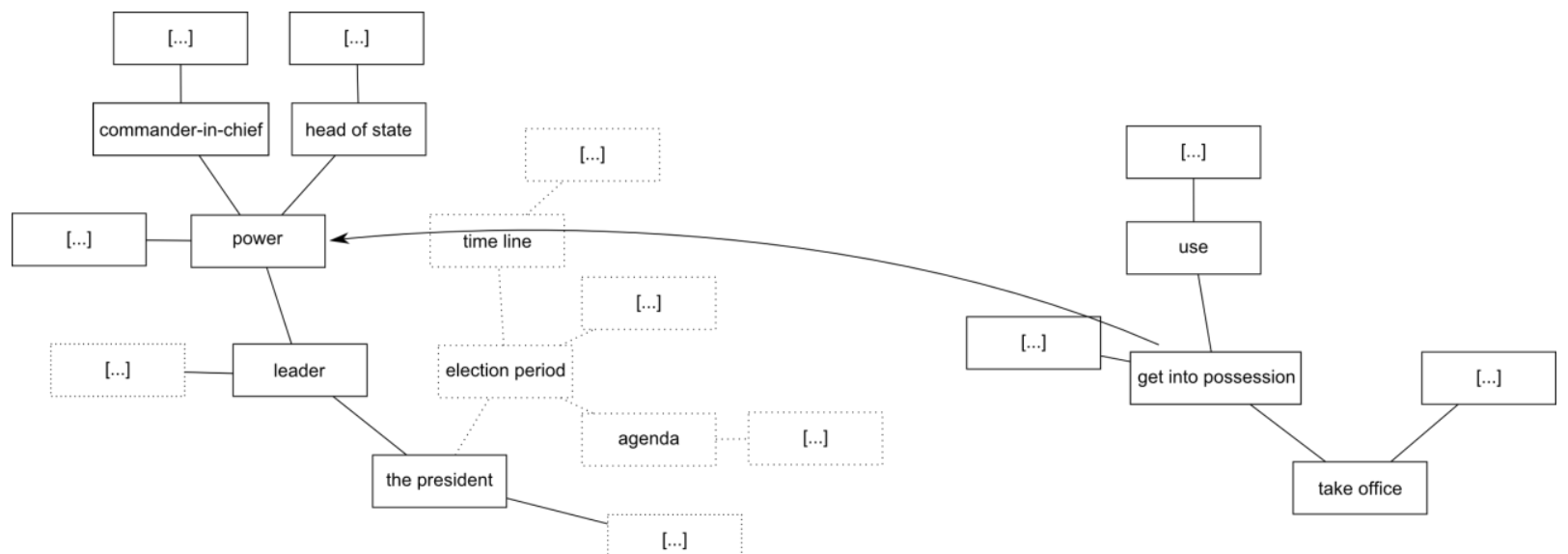

Figure 7: Matching cognitive models through semantic affordance for (6)

Comparing the cognitive model profiles of (5) and (6) shows that 'ein Amt antreten' and 'to take office' activate different cognitive models of [the president]. [ein Amt antreten] is associated with the primary cognitive model [beginning of term]. This primary model is connected to a number of different secondary models. Semantic affordances of these secondary models like, for example, "begin the political work" around [setting up a team] and "begin a new political phase" for [intent] associate with [the president]. Affordances like "enacting political plans" or "setting up political strategies" of the secondary cognitive model [agenda], which is connected to the primary model [election period] of [the president], denote means or implementations to "begin the political work" or to "begin a new political phase". Similarly, "forming political goals" as semantic affordance for [intent] blends in with "enacting political plans" of [agenda]. The president first of all forms a political plan including specific political goals that he then strives to execute during his presidency.

On the other hand, Figure 7 shows that the cognitive model profile for the English translation equivalent 'to take office' is different. The primary cognitive model is here [get into possession]. This model connects to the secondary cognitive model [power] of [the president]. The semantic affordances of [get into possession] including "obtain", and 
"being able to lose" as well as of the secondary cognitive model [use] under [get into possession] including affordances like "take advantage of" and "intention" thereby combine with [commander-in-chief] and [head of state] under [power] of [the president]. It is semantic affordances like "giving orders", "operational planning", and "leadership of political staff", as well as "legislative powers" of [commander-in-chief] and [head of state] which form a coherent state of affairs together with the affordances of [get into possession] and [use]. For example, the president can use his power to influence legislature by vetoing or promoting bills or deploy military troops in accord with his political motivations. Again we arrive at a coherent picture based on mutually related semantic affordances across distinct cognitive model profiles.

Summing up, it has become obvious that the German and English translation equivalents differ in their respective meanings. The predicates select distinct cognitive models in the cognitive model profiles of 'der Praesident' and 'the president' respectively via semantic affordances. While (5) largely promotes an agenda reading, (6) concentrates on power and influence.

Consequently, we see that translating from one language to another requires conceptual change. As discussed eaerlier, a speaker who translates from (3) to (4) or (5) to (6) and vice versa must construct the meanings of the words differently: the evoked conceptualizations vary. In the next section, I will discuss some of the implications for language teaching and learning.

\section{IMPLICATIONS FOR LANGUAGE TEACHING AND LEARNING}

Understanding that switching between languages means switching between different conceptualizations of the world calls for a change of perspective in language teaching and learning. Taking this seriously, the following claims are a first guideline on how to enact the conceptual change view in the language classroom:

a) The minimal unit in vocabulary learning is the clause. Single words or other sub-clausal units do not suffice for coming to grips with semantic affordances and conceptual change. As illustrated by the examples discussed earlier, semantic affordances unfold first of all between different parts of speech in a clause.

This claim implies that traditional vocabulary learning along lists of single words should be abandoned once and for all. Vocabulary should be learned as words-in-context in order to illustrate conceptual change that emerges when interpreting translation equivalents. Teachers should direct learners towards conceptual change by having them explicate relevant cognitive model profiles and compare distinct semantic affordances within these profiles across languages. Only in this way can learners arrive at an adequate understanding of the target language, contrasting lexicosemantic regularities and idiosyncrasies of their native language and the target language. ${ }^{1}$

A practical way to get learners explicate cognitive model profiles and semantic affordances lies in the analysis of the wider co-text of a given expression. Referring back to (5) and (6), the following examples, which are taken from WebCorp (available online at http://www.webcorp.org.uk/live/, last accessed on 10 Oct., 2012), could be used to help learners construct a cognitive models profile of [the president]. The italicized expressions provide the relevant information:

(1) Secretary Paul O'Neill has revealed that the President took office in January 2001 fully intending to invade Iraq (http://www.twf.org/News/Y2004/0111-Before911.html)

(2) The first power the Constitution confers upon the president is the veto.

(http://en.wikipedia.org/wiki/President_of_the_United_States)

(3) $[\ldots]$ the president commands and directs the military $[\ldots]$

(http://en.wikipedia.org/wiki/President_of_the_United_States)

(4) the president is responsible for the protection of Americans

(http://en.wikipedia.org/wiki/President_of_the_United_States)

(7), for instance, alludes to the president's role as commander-in-chief. (8), on the other hand, to his function as legislator. (9) refers again to [commander-in-chief], while (10) points to a moral obligation which could lead to a cognitive model in the form of [take care of citizens].

This works in a similar way for 'to take office':

(5) When a new president takes office, all the U.S. attorneys are asked to step down, so that the new president can install the people he/she wants. (COCA)

(6) $[\ldots]$ the possibility that embryonic stem cell research, a promising avenue of scientific inquiry that provokes moral objections because it involves the destruction of embryos, may be restricted once George W. Bush takes office as president. (COCA)

(7) Whoever takes office will decide whether the nation commits to spending hundreds of billions of dollars on a motel on the moon, or invests in space projects of tangible benefit-space science, environmental studies of Earth, and readying the world for protection against a spaceobject strike. (COCA)

\footnotetext{
${ }^{1}$ In section $4 \mathrm{I}$ have begged the question as to how large the word span for interpreting a keyword should be. A clause seems to be the most reasonable answer to me, as this is the smallest grammatical unit that expresses a proposition. As illustrated by all the examples in this paper, it is propositions which lay at the heart of meaning construction. To say it with predicate logic, the minimal unit of meaning construction is the assigning of a property in terms of $\mathrm{F}(\mathrm{a})$, where ' $\mathrm{F}$ ' stands for a property and ' $\mathrm{a}$ ' for an individual. $\mathrm{F}(\mathrm{a})$ means then that the property $\mathrm{F}$ is assigned to the individual a.
} 
(11)-(13) all allude to getting into possession of power. In (11) the president obtains the power to install new U.S. attorneys. (12) refers to the fact that the president is empowered to influence scientific conduct through the laws he passes or not. On the other hand, (13) points to the president's power over the national budget. These examples thus allude to a cognitive model profile with cognitive models like [get into possession] and [use] that we also included before in our analysis of (5) and (6).

On the other hand, German examples around 'ein Amt antreten' including

(8) George Bush trat sein Amt mit dem erklärten Vorsatz an, „Ehre und Würde“ im Weißen Haus wiederherzustellen. (http://www.zeit.de/2003/30/WMD, last accessed on 10 Sept., 2012)

("George Bush took office with the declared intent to restore the honor and dignity of the White House.")

(9) Schauprozess in Teheran, Vergewaltigungen in den Gefängnissen, ungeklärte Foltermorde von Häftlingen - der neue Justizchef des Iran tritt sein Amt an während der schwersten Krise der Islamischen Republik seit ihrer Gründung.

("Show trial in Teheran, rapes in prisons, open cases of torture murders of prisoners - the new chief of justice takes office during the most severe crisis of the Islamic Republic since its foundation.") (http://www.tagesspiegel.de/meinung/kommentare/portraet-sadegh-laridschani-neuer-justizchef-im-iran-der-kulturelleninvasion-entgegentreten/1581320.html, last accessed on 10 Sept., 2012)

Support the election period reading. The German noun 'Vorsatz' ("intent") in (14) refers to a person's willful intent for a new phase of life. The situation is similar for (15). 'Schauprozess in Teheran, Vergewaltigungen in den Gefängnissen, ungeklärte Foltermorde von Häftlingen' (“show trial in Teheran, rapes in prisons, open cases of torture murders of prisoners") are a moral stain for Iranian justice. It is thus considered the new chief of justice's duty to deescalate the situation, restoring law and order. His taking office is thereby depicted as a potentially new phase for the legal system. Although the chief's intent to fight the crisis is not explicitly mentioned, it can be presupposed on the basis of the nature of his office. Putting this information together, the learner can construct a cognitive model profile [ein Amt antreten] similar to the one in Figure 6.

To sum up: it is the wider co-text that provides language learners with the information necessary to construct cognitive model profiles and to understand the semantic affordances of expressions in a given language. This method is not restricted to making use of the co-textual environment alone. Cognitive models of a profile can also be found in a top down process of inquiry. Learners might just think of attributes and properties of a base model like [the president] and add them to the profile in terms of primary and secondary models.

Constructing cognitive model profile lays the basis for my second claim:

b) Language teachers should be aware that learning a second or foreign language is based on conceptualizations in one's L1. These lay the basis on top of which conceptualizations in a second or foreign language are built.

It is important to keep in mind that language learners are not blank slates. Learning a new language always means learning a new language on top of the languages that one already knows. For example, a native speaker of a satelliteframing language conceptualizes actions or activities via a much stronger motion imagery than a speaker of a verbframing language. Teachers should integrate these cognitive predispositions into the learning process. For example, learners should draw cognitive maps like in Figures 3 and 4 or 5 and 6 for translation equivalents and analyze them with regard to similarities and differences. Actively identifying and reflecting on the distinct conceptualizations help learners detect and understand language specific regularities in their L1 as well as in the second or foreign language. They can thus better internalize meaning construction in the target language and become more aware of potential misinterpretations on the basis of L1 transfer.

My third claim is that

c) TaLCC support learner autonomy, competence, and relatedness. Within this context, learners are more motivated to learn than with other teaching and learning methods.

This claim is based on the main assumptions of Self-Determination Theory (SDT) (Deci and Ryan 1985). SDT assumes that people have three basic psychological needs: autonomy, competence, and relatedness. People want to decide about their course of action, be able to reach their goals and tackle problems by themselves as well as be accepted and respected by others. Learning environments supporting these needs have thereby a positive impact on learner motivation and performance (e.g., Benware and Deci 1984; Grolnick and Ryan 1987; Vansteenkiste et al. 2008). Within such an environment learners process information on a deeper level, which also results in better knowledge retention, creative thinking and in-depth understanding. TaLCC serve all three needs: learners build new knowledge through self-regulated learning. Constructing cognitive model profiles is an autonomous process by which learners actively interpret linguistic forms in accord with how they and others cognize about the world. They contrast these conceptualizations and identify similarities and differences, thus familiarizing themselves with the idiosyncrasies of the contrasted languages.

They thereby experience themselves as competent "linguists". Learners are well experienced with the tools they use like interpreting words in context via semantic affordances, conceptualizing linguistic input, and contrastive analysis. Explicating these processes might initially require some guidance by the teacher. For example, learners might need some incentive as to how to structure conceptualizations via cognitive model profiles. But these are technicalities that, as soon as they have been addressed, will not take up much space in the learning process and will be put to use intuitively. 
Relatedness stems from the fact that learners can fall back on their own way of doing things. Teaching and learning rely here primarily on the leaner's current knowledge state. The teacher picks learners up at their conceptualizations in their L1 and guides them to finding out about how these conceptualizations change in another language. The teacherlearner interaction is here a mutual one that relies on strong dialogic ties where all participants exchange their viewpoints and interpretations.

\section{CONCLUSION}

In this paper I have presented a view of language teaching and learning as TaLCC based on soft conceptual change. Similarly to science education, language learning in general and vocabulary learning in particular can and should be taught by making use of what learners already know from their L1. In other words, new knowledge is built on top of existing knowledge. I argued that learning word meanings in a foreign language should be done via contrastive analyses of cognitive model profiles which I borrowed from Evans' LCCM Theory. This scaffolds the learner's understanding and internalization of lexico-semantic regularities and idiosyncrasies in both his L1 and the second or foreign language.

Constructing cognitive model profiles might require instructional guidance at the beginning but relies by itself on competencies the learner already has within the context of his L1. In TaLCC the learner uses intuitive tools for meaning construction like making use of a word's co-text through semantic affordances, conceptualizing linguistic input, and contrasting between different conceptualizations. I discussed how learners can construct cognitive model profiles by theoretical inquiry and by making use of the co-textual environment.

In addition, I noted that TaLCC go hand in hand with Self-Determination Theory, supporting learner motivation and performance through facilitating autonomy, competence, and relatedness in the teacher-learner interaction.

Future research should investigate how TaLCC can be put into practice most efficiently in the language classroom. What kinds of means are there to make this sort of teaching and learning style practicable for both teachers and learners? What materials should be developed and how? Do TaLCC work for everyone similarly, or are there any differences, for example, with regard to different learning styles or motivational states of learners? In addition, can TaLCC be used in other areas of language teaching and learning such as grammar instruction? What about polyglot learners? How and, if so, to what extent, do one's L2, L3 etc. influence one's learning a new language? Answers to these and similar questions will help to make the language classroom a more effective and more enjoyable place for both teachers and learners alike.

\section{REFERENCES}

[1] Alexander, R. J. (2004). Towards Dialogic Teaching: Rethinking Classroom Talk. York Dialogos.

[2] Benware, C. A., and Deci, E. L. (1984). "Quality of Learning with an Active versus Passive Motivational Set." American Educational Research Journal 21: 755-65.

[3] Brophy, J. E. (2010). Motivating Students to Learn. New York: Routledge.

[4] Craig, S., Gholson, B., Ventura, M., Graesser, A., and The Tutoring Research Group. (2000). "Overhearing Dialogues and Monologues in Virtual Tutoring Sessions: Effects on Questioning and Vicarious Learning." International Journal of Artificial Intelligence in Education 11: 242-253.

[5] Deci, E. L., and Ryan, R. M. (1985). Intrinsic Motivation and Self-Determination in Human Behavior. New York: Plenum.

[6] Evans, V. (2006). "Lexical Concepts, Cognitive Models and Meaning-Construction." Cognitive Linguistics 17 (4): $491-534$.

[7] Evans, V. (2009). "Semantic Representation in LCCM Theory." In New Directions in Cognitive Linguistics, ed. by Stéphanie Pourcel, and Vyvian Evans, 27-46. Amsterdam and Philadelphia: Benjamins.

[8] Evans, V. (2010a). "Figurative Language Understanding in LCCM Theory.” Cognitive Linguistics 21 (4): 601-662.

[9] Evans, V. (2010b). "On the Nature of Lexical Concepts." Belgrade Journal of English Linguistics and Literature Studies (BELLS), vol. 2: 11-46.

[10] Everett, D. (2005). "Cultural Constraints on Grammar and Cognition in Pirahã." Current Anthropology 46 (4): $621-646$.

[11] Feller, S. (2010). Lexical Meaning in Dialogic Language Use. Amsterdam and Philadelphia: Benjamins.

[12] Fisher, R. (2007). "Dialogic Teaching: Developing Thinking and Metacognition through Philosophical Discussion." Early Child Development and Care 177 (6-7): 615-631.

[13] Fraser, B., Tobin, K., and McRobbie, C. (eds). (2011). Second International Handbook of Science Education. Dordrecht et al.: Springer.

[14] Grolnick, W. S., and Ryan, Richard M. (1987). “Autonomy in Children's Learning: An Experimental and Individual Difference Investigation.” Journal of Personality and Social Psychology 52: 890-898.

[15] Haenen, J., Schrijnemakers H., and Stufkens, J. (2003). "Sociocultural Theory and the Practice of Teaching Historical Concepts." In A. Kozulin, B. Gindis, V. S. Ageyev, and S. M. Miller (Eds.) Vygotsky's Educational Theory in Cultural Context (pp. 246-266). Cambridge: Cambridge University Press.

[16] Hewson, P. W. (1992). "Conceptual Change in Science Teaching and Teacher Education." Paper presented at a meeting on 'Research and Curriculum Development in Science Teaching'. Madrid. Spain.

[17] Levinson, S. (2009). "Language and Mind: Let's Get the Issues Straight!" In Making Sense of Language. Readings in Culture and Communication, ed. by Susan Blum, 95-104. Oxford: Oxford University Press.

[18] Mason, O. (2007). "The Weight of Words: An investigation of Lexical Gravity." In B. Lewandowska-Tomaszczyk, and P. Melia (Eds.) Proceedings of PALC'97 (pp. 361-375). Lodz: Lodz University Press.

[19] Meadows, L. (2008). "Teacher Knowledge about Inquiry. Incorporating Conceptual Change Theory." In E. Abrams, S. Southerland, and P. Silva (Eds.) Inquiry in the Classroom: Realities and Opportunities (pp. 177-190). IAP. 
[20] Pavlenko, A. (2002). “Conceptual Change in Bilingual Memory: A Neo Whorfian Approach.” In M. Paradis, and F. Fabbro (Eds.) Advances in the Neurolinguistics of Bilingualism. Essays in Honor of Michel Paradis (pp. 69-94). Udine: Udine University Press.

[21] Sinatra, G. M., and Taasoobshirazi G. (2011). "Intentional Conceptual Change. The Self-Regulation of Science Learning." In B Zimmerman, D. H. Schunk (Eds.) Handbook of Self-Regulation of Learning and Performance (pp. 203-216). New York: Routledge.

[22] Sinclair, J. (1991). Corpus, Concordance, Collocation. Oxford et al.: Oxford University Press.

[23] Sinclair, J. (1998). "The Lexical Item.” In E. Weigand (Ed.) Contrastive Lexical Semantics (pp. 1-24). Amsterdam and Philadelphia: Benjamins.

[24] Stubbs, M. (2001). Words and Phrases. Corpus Studies of Lexical Semantics. Oxford and Malden: Blackwell Publishers.

[25] Thagard, P. (1992). Conceptual Revolutions. Princeton and Chichester: Princeton University Press.

[26] Torres, P. L., and de Cássia Veiga Marriott, R. (Eds.). (2010). Handbook of Research on Collaborative Learning Using Concept Mapping. Hershey: Information Science Reference.

[27] Vanderveken, D. (2009). Meaning and Speech Acts. Principles of Language Use, vol. 1. Cambridge: Cambridge University Press.

[28] Vansteenkiste, M., Ryan, R. M., and Deci, E. R. (2008). "Self-Determination Theory and the Explanatory Role of Psychological Needs in Human Well-Being." In L. Bruni, F. Comim, and M. Pugno (Eds.) Capabilities and Happiness (pp. 187-223). New York: Oxford University Press.

[29] Weigand, E. (2005). "The Role of Lexical Data in Pragmatics." In A. Cruse et al. (Eds.) Lexicology. An International Handbook on the Nature and Structure of Words and Vocabularies, vol. II (pp. 1696-1702). Berlin, New York: de Gruyter.

[30] Zimmerman, B. J., and Schunk, D. H. (2011). Handbook of Self-Regulation of Learning and Performance. New York: Routledge.

Sebastian Feller obtained his PhD in English Linguistics from the University of Muenster in Germany. He is currently working for the Social Situation Awareness project at A*STAR Institute of High Performance Computing in Singapore. The project's focus is intelligent tutoring agents for language learning. In the past he taught as lecturer at the Department of English Studies at Majan University College in Muscat, Oman. Sebastian also worked as a school teacher for English in Germany. He is board member of the International Association of Dialogue Analysis, which investigates dialog from an interdisciplinary standpoint. 